\title{
Writing words from pictures: What representations are activated, and when?
}

\author{
PATRICK BONIN and MICHEL FAYOL \\ LAPSCO/CNRS, Université Blaise-Pascal, Clermont-Ferrand, France
}

\begin{abstract}
In three experiments, the nature of the representations involved in written picture naming and the time course of their activation were investigated. French participants had to produce picture names while hearing distractors. In Experiment 1, distractors semantically related to the picture names yielded a semantic interference effect when a stimulus onset asynchrony (SOA) of - $150 \mathrm{msec}$, but not when a SOA of $0 \mathrm{msec}$, was used, in both spoken and written picture naming. Experiment 2 showed that the semantic interference effect was not located at the conceptual level. In Experiment 3, participants wrote down picture names while hearing semantically related, phonologically related, both semantically and phonologically related, or unrelated distractors, presented at both SOAs. A semantic interference effect was obtained with phonologically unrelated distractors but was eliminated with phonologically related distractors. Facilitatory effects of phonologically related distractors were found at both SOAs. The implications of the findings for written picture naming are discussed.
\end{abstract}

Although speech production research has given rise to models that describe the processes and representations underlying lexical access, the topic of lexical access in the written productions of normal subjects has not been investigated in a systematic experimental way. As a result, the study of lexical access in speech is far more advanced than that of lexical access in writing (Bonin, 1995; Bonin, 1997; Bonin \& Fayol, 1996a, 1996b). The present study attempts to bridge this gap and to address the general question of the nature of the representations involved in written picture naming and of their time course of activation.

Why should we address this issue? For a long time, it was assumed that writing is parasitic on speech (Rapp, Benzing, \& Caramazza, 1997). According to this view, written and spoken word production involve similar processes. However, this traditional view has not as yet received strong empirical support. To the best of our knowledge, few experimental studies involving normal adults have investigated the extent to which the processes and the representations involved in written word production resemble those involved in spoken word production (Bonin, Fayol, \& Gombert, 1997, 1998; Bonin, Fayol, \& Peereman, 1998). The purpose of the present study was to shed light on this similarity problem. In particular, we focus on access to semantic and orthographic-phonological ${ }^{1}$ representations during the production of isolated words from

\footnotetext{
The authors thank Bob Lorch, W. La Heij, and an anonymous reviewer for their very helpful comments and suggestions concerning this manuscript. The authors are also grateful to Fabienne Baudot-Bonin for drawing the figures. Correspondence concerning this article should be addressed to P. Bonin, Laboratoire de Psychologie Sociale de la Cognition (LAPSCO), Université Blaise-Pascal, 34 avenue Carnot, 63037 Clermont--Ferrand, France (e-mail: patrick.bonin@srvpsy.univbpclermont.fr).
}

pictures. Our basic assumption was that, if we were to find similar effects, this would indicate that similar processes are involved in both forms of language production.

In most speech production models, expressing the name of a pictured object involves three major levels of processing: conceptualizing, formulating, and articulating (Bock \& Levelt, 1994; Dell, 1986; Levelt, 1989, 1991, 1992; Roelofs, 1992; Schriefers, Meyer, \& Levelt, 1990). Formulating involves lemma retrieval and access to the corresponding phonological form, referred to as the lexeme. Lemmas encode the meanings and the syntactic properties of words (e.g., for the French word lune (moon), the lemma of lune encodes the facts that it is a noun and that its gender is feminine), but they do not contain phonological information (Levelt, 1989) or orthographic information. A keenly debated topic is whether the levels of lemma retrieval and phonological encoding are connected in a strict discrete-serial way (Butterworth, 1989; Levelt, 1989; Levelt et al., 1991a, 1991b; Roelofs, 1992; Roelofs, Meyer, \& Levelt, 1996; Schriefers et al., 1990), in a cascaded way (Humphreys, Riddoch, \& Quinlan, 1988; Jescheniak \& Schriefers, 1997, 1998; Peterson \& Savoy, 1998) or in an interactive way (Dell, 1986, 1988, 1990; Dell \& O'Seaghdha, 1992). Schriefers et al., as well as Levelt et al. (1991a, 1991b) and, more recently, Roelofs et al. (1996, 1998), have made a strong claim that the lemma and the lexeme levels are strictly serial.

According to the strict discrete-serial view, the concept to be expressed (which, in most psycholinguistic experiments, is activated by a picture) sends activation to its connected lemmas. The most strongly activated lemma is selected, and the activation of semantically related lemmas is then turned off. Thus, only the selected lemma becomes phonologically encoded (by activating its lexeme). The cascaded view differs from the discrete--serial view 
in that it allows a feedforward transmission of activation from the activated lemmas to their connected lexemes before a selection step in lemma processing has taken place. As a consequence, phonological encoding is not restricted to the selected lemma. Finally, the interactive view is similar to the cascaded view, except that it allows feedback activation from the lexeme level to the lemma level (Dell, 1986; Dell \& O’Seaghdha, 1992).

The main empirical support for the lemma-lexeme distinction and for the strict seriality assumption between these two levels was provided by Schriefers et al.'s (1990) study, which will be discussed below.

As far as the involvement of semantic representations is concerned, there is evidence that in both spoken and written picture naming, semantic representations related to the concept to be named are activated. Evidence for this comes from analyses of speech errors (Harley, 1984; Levelt, 1989), from clinical neuropsychological studies (Bub, Black, Hampson, \& Kertesz, 1988; Kinsbourne \& Warrington, 1964), and from experimental research on normal subjects (Schriefers, 1990, 1992). Using the pictureword interference paradigm, Schriefers et al. (1990) showed that semantically related distractors auditorily presented $150 \mathrm{msec}$ before picture onset delayed spoken picture naming, compared with unrelated controls. Such an effect is referred to as the semantic interference effect (La Heij et al., 1990; La Heij, Dirkx, \& Kramer, 1990; La Heij, Starreveld, \& Steehouwer, 1993; Rayner \& Springer, 1986; Schriefers et al., 1990; Starreveld \& La Heij, 1995, 1996). For instance, a picture of a dog is named more slowly when accompanied by the semantically related word $f o x$ than when accompanied by the unrelated word nut. More precisely, Schriefers et al.'s study showed that a semantic interference effect was observed when auditory distractors were presented early (using a stimulus onset asynchrony [SOA] of $-150 \mathrm{msec}$ ), but not when presented late (using SOAs of 0 and $+150 \mathrm{msec}$ ), in the time course of spoken picture naming. Semantic interference effects have also been reported with visually presented distractors and appear to occur in a restricted temporal window (with SOA values ranging from -200 to $+200 \mathrm{msec})^{2}{ }^{2}$

The findings concerning the time course of phonological facilitation in spoken picture naming are not entirely consistent. Schriefers et al. (1990) found that phonological representations were only activated late in the time course of lexical access, when compared with semantic representations. In addition, no SOA was found at which both semantic interference and phonological facilitation were observed. Schriefers et al. interpreted these findings as supporting the discrete-serial view, according to which semantic activation is discretely transmitted to phonological representations (lexemes). In contrast, other studies have reported early effects of phonological similarity (e.g., Meyer \& Schriefers, 1991; Starreveld \& La Heij, 1996). Because in the latter study the distractors were presented visually rather than auditorily, a difference in distractor modality may be responsible for this discrepancy.
Most models of written picture naming are provided by cognitive neuropsychologists (Caramazza \& Hillis, 1990; Ellis, 1982, 1984, 1988; Margolin, 1984). The identified processing levels are, to some extent, similar to those involved in spoken picture naming (Bonin, Fayol, \& Gombert, 1998). Written picture naming involves a semantic level and a lexeme level. More specifically, in the case of writing, the lexemes provide orthographic information. Most models of written picture naming do not explicitly specify the time course of activation of semantic and lexeme representations, and certain advocates of these admit, at least implicitly, a discrete feedforward transmission of activation between semantic and lexeme representations (e.g., Ellis, 1982, 1984, 1988; but see Caramazza \& Hillis, 1990). However, the experimental evidence from normal subjects necessary to support this view (or an alternative view) is still lacking. For this reason, the goal of the present study was to determine whether the strict discrete seriality assumption, which has been strongly advocated by Schriefers et al. (1990) for spoken picture naming, might also receive empirical support from normals for written picture naming. Although their main assumptions have been challenged in the last couple of years, Schriefers et al.'s study is one of the most frequently cited pieces of evidence for the strict discrete seriality assumption in spoken picture naming, and because this seriality view is still advocated (Roelofs et al., 1996), we chose to adhere to the general rationale underlying Schriefers et al.'s study, closely following their logic and using the same experimental paradigm as the one they usednamely, the picture-word interference paradigm. In the first experiment, we were concerned with the time course of activation of semantic representations. We investigated whether, in written picture naming, a semantic interference effect would be observed in the same temporal window as that in spoken picture naming, using the picture-word interference paradigm and auditorily presented distractors, as in Schriefers et al.

\section{EXPERIMENT 1}

The goal of Experiment $l$ was to assess whether access to semantic representations proceeds in similar ways in spoken and written picture naming. We wanted to determine whether semantic interference, taken as a marker of the involvement of semantic representations, follows the same time course of activation in written picture naming as in spoken picture naming. Using precisely the abovementioned picture-word interference paradigm, we tested whether this effect could be observed at the same SOA value as that at which Schriefers et al. (1990) observed semantic interference (i.e., $-150 \mathrm{msec}$ ). To this end and to permit comparisons with Schriefers et al.'s study, in which different populations and materials were used, a spoken picture naming task was included, and the distractors were presented auditorily, as in Schriefers et al.

In Experiment 1, the participants had to write down or say aloud the names of pictures while hearing distractors 
that were semantically related to the picture names, unrelated to them, or neutral (a blank noise). As a silent control condition, the pictures were presented without distractors. The auditory distractors were presented $150 \mathrm{msec}$ before the picture onsets $(\mathrm{SOA}=-150 \mathrm{msec})$ or simultaneously with the picture onsets $(\mathrm{SOA}=0 \mathrm{msec})$. The main dependent variables were written and spoken latencies and errors. In the light of Schriefers et al.'s (1990) findings, we predicted a semantic interference effect for both written and spoken picture naming with an SOA value of $-150 \mathrm{msec}$, but not with an SOA value of $0 \mathrm{msec}$.

\section{Method}

Participants. The experiment was run with 48 students from Bourgogne University, 24 per output modality. The participants received course credit. All were native speakers of French, had normal or corrected-to-normal vision, and had no known hearing deficits.

Materials. Twenty line drawings of common objects were used as the experimental pictures. Six additional, practice pictures were used as warm-ups at the beginning of the experiment. Some of the drawings were selected from Snodgrass and Vanderwart's (1980) corpus, and the remainder were selected from a pool of pictures we had used in other experiments on language production (Bonin, 1995; Bonin, Fayol, \& Gombert, 1997, 1998). The mean frequency of the picture names was 5,255 per 100 million, and the mean number of letters and syllables was six and two, respectively. Frequency counts were taken from the Brulex database (Content, Mousty, \& Radeau, 1990). The auditory distractors either belonged to the same semantic category as the picture name (semantic condition) or were unrelated to the target picture name (unrelated condition). In the neutral condition, the pictures were accompanied by a stretch of white noise (noise condition). Since the sets of auditory distractors differed across experimental conditions (see Appendix A), we were careful to avoid allowing any possible difference between them to contribute to response time (RT) differences between experimental conditions. The mean frequency was 5,220 for the semantic condition and 4,870 for the unrelated condition; the mean number of letters was six for both conditions, and the mean number of syllables was 1.8 for the semantic condition and 1.4 for the unrelated condition. Finally, the acoustic duration of the distractors was the same across conditions, $798 \mathrm{msec}$ on average.

Design. The experimental design included two crossed withinsubjects factors-namely, distractor type, with four levels (silence, silent; white noise, noise; semantically related to picture name, semantic; and unrelated to picture name, unrelated), and SOA, with two levels ( $\mathrm{SOA}=-150 \mathrm{msec}$ and SOA $=0 \mathrm{msec}$ )-and one crossed between-subjects factor, output type, with two levels (naming and writing). These two SOAs were chosen on the basis of Schriefers et al.'s (1990) study. The pictures were presented four times with an SOA of 0 msec and four times with an SOA of $-150 \mathrm{msec}$. One group of participants started with $\mathrm{SOA}=-150 \mathrm{msec}$ and then proceeded to the condition with $\mathrm{SOA}=0 \mathrm{msec}$. This order was reversed for the second group of participants. Each picture was paired with each of the four distractors. The resulting 80 distractor-picture pairs were divided into four sets. Each set was constrained in such a way that each of the 20 pictures occurred once and each of the four distractor types occurred five times. Likewise, every participant saw each picture four times (for a given SOA), once with each type of distractor. However, any given picture occurred only once in a block of 20 critical items. For each subgroup of items, different random orders were created while respecting the following criteria. No picture could be preceded by a phonologically or semantically related picture or distractor on the previous trial. For each SOA, the blocks were randomly presented. Different randomized sequences were employed in the subgroups of items testing the two different SOAs.
Apparatus. The experiment was run using PsyScope, Version 1.0.1 (Cohen, MacWhinney, Flatt, \& Provost, 1993; Vaughan \& Yee, 1994), on a Macintosh LC II. The computer controlled the presentation of the pictures and distractors and recorded the latencies. A graphic tablet (WACOM) and a contact pen (SP-210) were used to record graphic latencies. A microphone (Aiwa stereo; impedance, $>1 \mathrm{~kW} ;-74 \mathrm{~dB}$ ) was used to record articulatory latencies. The distractors were recorded with SoundEditPro and presented via digital headphones.

Procedure. The participants were tested individually and randomly assigned to one of the two levels of the output factor. At the beginning of the session, they received a booklet showing the target pictures with their names. The participants were told to study the names of the pictures and to use only those names to refer to the pictures. As soon as they said they had looked at all the drawings and studied their names, the instructions were given. The participants were told that they would have to say aloud or, depending on the group, write down, as quickly as possible, the name of any given picture presented on the screen. They were told that a given picture would be accompanied by a word, a noise presented via the headphones, or a silence. They were required to pay no attention to the auditory distractors. The pictures were presented centered on the screen at a viewing distance of about $60 \mathrm{~cm}$. The experimenter monitored the participants' responses and scored them for correctness. The entire session lasted about $1 \mathrm{~h}$.

A test trial had the following structure. A ready signal (==-==) was presented for $500 \mathrm{msec}$, followed by a picture. Depending on the SOA condition, the onset of the distractor coincided with the picture onset $(\mathrm{SOA}=0 \mathrm{msec})$ or preceded it by $150 \mathrm{msec}(\mathrm{SOA}=$ $-150 \mathrm{msec}$ ). The participants said aloud or wrote down the name of the picture as quickly as possible.

For both output modalities, latencies were measured from picture onset to the initiation of the spoken/written response. In the case of the written responses, the latencies were timed as follows: The participants sat with the stylus right above the tablet, so that the latency was the time required to make contact after picture onset. For both spoken and written picture-naming latencies, observations were discarded from the analyses whenever any of the following conditions applied: The participant did not remember the picture name, a technical problem occurred, or an item other than the expected one was produced. Specifically in the case of written responses, observations were discarded when: A word was misspelled, the participant merely touched the tablet and paused (by paused, we mean that the participant waited for more than 1 sec without moving the stylus), or the participant wrote down a letter or two and then paused. For the spoken responses, observations were scored as errors when participants stuttered, produced nonlinguistic sounds (such as mouth clicks), or repaired the utterance after a dysfluency.

The picture was removed from the screen after the participant had initiated naming or writing. The next trial was presented after a pause of $5,000 \mathrm{msec}$.

\section{Results}

The exclusion criteria defined in the Procedure section were applied to the data. In addition, for both naming and writing, latencies exceeding two standard deviations above the participant and item means were discarded. Applying this set of criteria led us to exclude $5.2 \%$ of the data for naming and $2.4 \%$ for writing.

Latencies and errors were submitted to analyses of variance (ANOVAs) with output (naming, writing), SOA $(\mathrm{SOA}=0 \mathrm{msec}, \mathrm{SOA}=-150 \mathrm{msec}$ ), and distractor type (silent, noise, semantic, and unrelated) as experimental factors. To allow us to generalize over both participants 


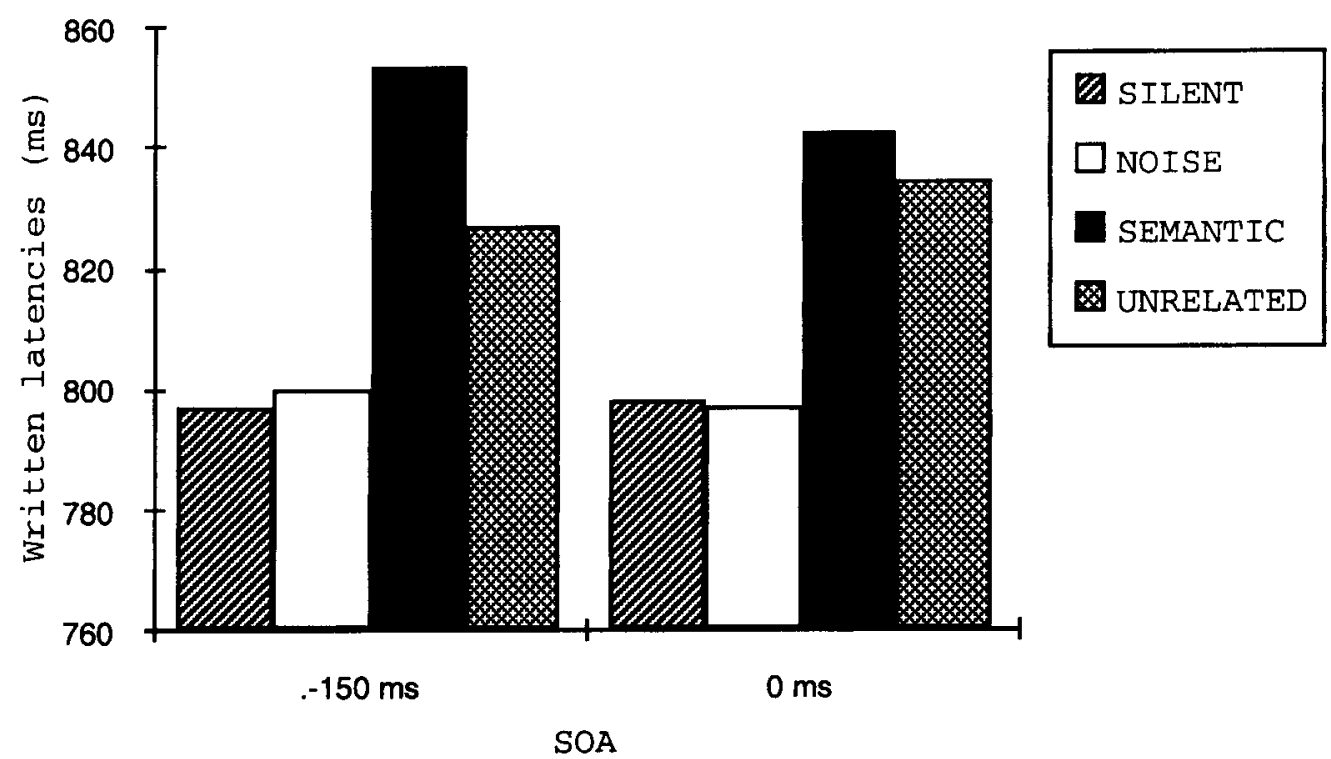

Figure 1. Mean latencies for written responses (in milliseconds) as a function of stimulus onset asynchrony (SOA) and distractor type in Experiment 1.

and items (Clark, 1973), two ANOVAs were carried out, one on the participant means $\left(F_{1}\right)$ and one on the item means $\left(F_{2}\right)$. For all analyses, the conventional level of .05 for statistical significance was adopted.

RTs were faster in the naming task than in the writing $\operatorname{task}\left[F_{1}(1,46)=17.47, M S_{\mathrm{e}}=79,207 ; F_{2}(1,19)=125.12\right.$, $\left.M S_{\mathrm{e}}=9,079\right]$. More importantly, RTs varied systematically as a function of the type of distractor $\left[F_{1}(3,138)=\right.$ $\left.88.67, M S_{\mathrm{e}}=1,481 ; F_{2}(3,57)=45.33, M S_{\mathrm{e}}=2,444\right]$. As can be seen in Figures 1 and 2, RTs were generally slower in the semantic and unrelated conditions than in the silent and noise conditions. These differences were confirmed for both tasks at both SOAs by Duncan tests (familywise error rate controlled at .05). Although the mean pattern as a function of type of distractor was similar in all four conditions, the magnitude of the distractor type effect differed reliably across the two SOAs $\left[F_{1}(3,138)=3.25, M S_{\mathrm{e}}=480 ; F_{2}(3,57)=2.85, M S_{\mathrm{e}}=\right.$ 426]. We were specifically interested in whether the semantic interference effect (i.e., the semantic - unrelated difference) varied in magnitude across the two SOAs. Planned comparisons showed that the semantic - unrelated difference was significant at the $-150-\mathrm{msec}$ SOA for both the naming task $(+31 \mathrm{msec})$ and the writing task $(+26 \mathrm{msec})$ but was not significant at the 0 -msec SOA for either the naming $(+16 \mathrm{msec})$ or the writing $(+8 \mathrm{msec})$ task.

The only significant effect in the error analyses was that the error rate was higher in the naming task $(5 \%)$ than in the writing task $(2 \%)\left[F_{1}(1,46)=8.33, M S_{\mathrm{e}}=0.0098\right.$; $\left.F_{2}(1,18)=15.06, M S_{\mathrm{e}}=0.0043\right]$.

\section{Discussion}

Experiment 1 clearly showed that a semantic interference effect can also be obtained in a picture-word interference task in which written names have to be produced. Of spe- cial importance is the fact that the semantic interference effect was observed with the same SOA value as that for spoken picture naming - namely, $-150 \mathrm{msec}$. At an empirical level, these findings replicate the semantic interference effect in spoken picture naming when using French rather than Dutch, as in Schriefers et al. (1990), and extend the effect to the written modality. The findings suggest that the same kind of representations underlies the semantic interference effect in naming and in writing and that the processes involved operate in the same temporal window.

Schriefers et al. (1990) argued for a lemma locus of the semantic interference effect in spoken picture naming as a result of their findings that (1) this effect was not obtained in an object recognition task and thus could not be ascribed to a conceptual level, since an object recognition task involves perceptual encoding and conceptual activation but no overt language production, and (2) at the SOA at which semantic interference was obtained, no effect of phonological facilitation was found, indicating that the semantic interference effect is not localized at the level where phonological facilitation is supposed to occur-the lexeme level.

Is the semantic interference effect localized at the conceptual level? In the light of the lack of a semantic interference effect in an object recognition task reported by Schriefers et al.(1990), we might be tempted to answer that it is not. However, these results are not conclusive, because Schriefers et al. used spoken responses and a different language (Dutch) than ours. Thus, the next experiment was designed to be a simple replication of Schriefers et al.'s third experiment, but using French material.

\section{EXPERIMENT 2}

The purpose of Experiment 2 was to test whether the semantic interference effect observed in Experiment 1 


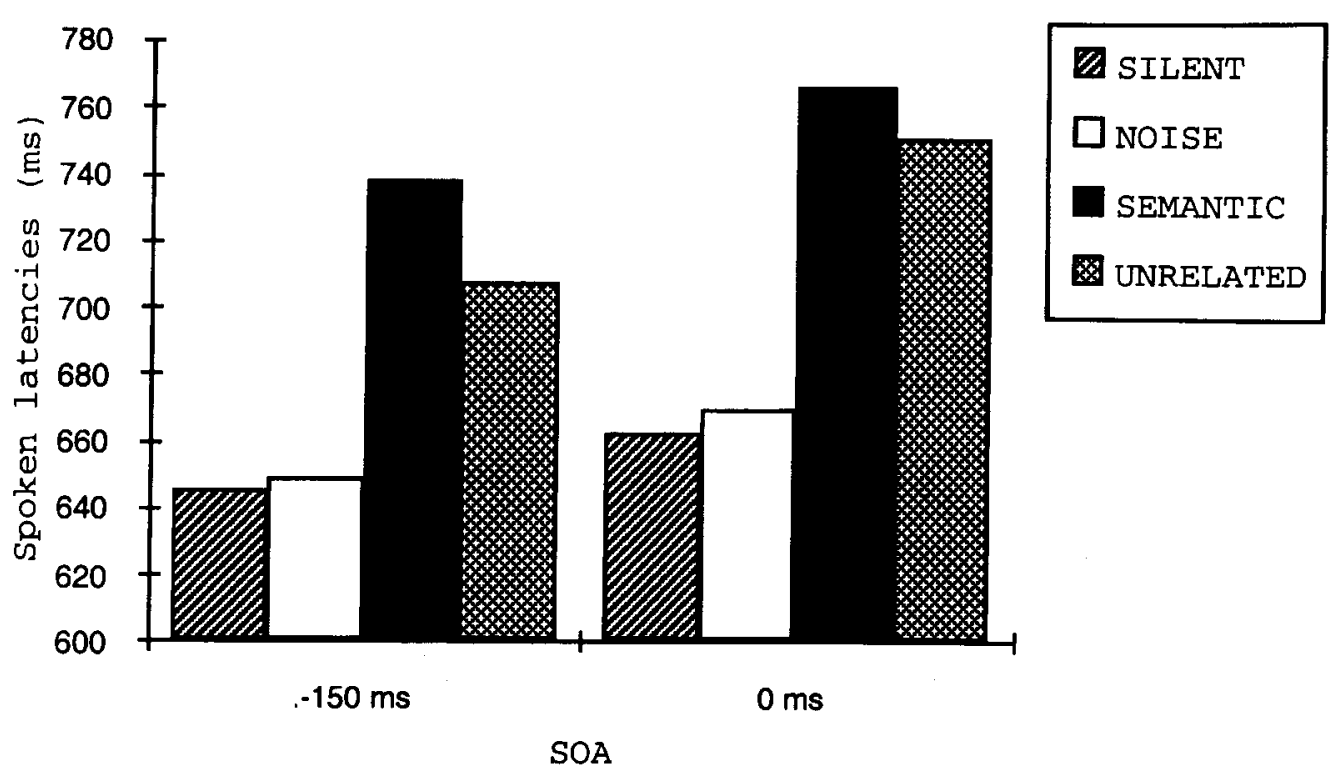

Figure 2. Mean latencies for spoken responses (in milliseconds) as a function of stimulus onset asynchrony (SOA) and distractor type in Experiment 1.

could be ascribed to a conceptual level involved in lexical access. The rationale was that if the semantic interference effect is thought to arise at a conceptual level, it should manifest itself in a task that requires conceptual activation but no overt language production. Thus, an experimental task requiring perceptual encoding and conceptual activation but no overt language production was designed, and as in Schriefers et al.'s (1990) study, we used an object recognition task. In this task, the participants had to use two pushbuttons to quickly indicate whether or not they thought a given picture had been seen in a previously presented set of pictures. The response was categorized as old or new accordingly. A given picture either was accompanied by the same auditory distractors as those in Experiment 1 or was presented without a distractor. Given that the semantic interference effect was reliably observed in Experiment 1 with an SOA value of $-150 \mathrm{msec}$, only that SOA value was used. Thus, we tested whether a semantic interference effect would be observed with an SOA of -150 msec on the RTs of participants categorizing the pictures as old or new.

\footnotetext{
Method

Participants. Twenty students from Bourgogne University took part in the experiment and were given course credit for their participation. All had normal or corrected-to-normal vision and no known hearing deficits. None of them had participated in the previous experiment.

Materials. The materials were the same as those in Experiment 1 (see Appendix A). The pictures were divided into two sets of 10 pictures each (Set 1 and Set 2). For half of the participants, Set 1 was used in the presentation phase, and both sets were used in the recognition phase. For the remaining half, Set 1 and Set 2 were reversed.
}

Design. There were two crossed within-subjects factorsnamely, distractor type, with four levels (silent, noise, semantic, and unrelated) and response type (old and new), and one crossed betweensubjects factor, set type, with two levels ( 1 and 2 ). Applying the same criteria as those in Experiment 1, four groups were created, consisting of 20 picture-distractor pairs. There was an equal number of new and old responses in each block. For each item subgroup, different random orders were created while applying the same criteria as those described in the previous experiment.

Apparatus. The apparatus was the same as that in Experiment 1.

Procedure. The beginning of the session was identical to that of Experiment 1 . The participants were told that they would have to decide as quickly as possible whether a given picture presented on the screen was new or old. They indicated their decision by means of two pushbuttons, using the first two fingers of their preferred hand. The assignment of fingers to the buttons was counterbalanced across participants. They were told that a given picture would be accompanied by a word, a noise, or a silence, presented via headphones. However, they were asked to pay no attention to the auditory distractors. The session lasted about half an hour.

A test trial was performed with exactly the same structure as that in Experiment 1. RTs were measured from the onset of picture presentation.

\section{Results}

The procedures for analyzing the data were analogous to those described for Experiment 1. The ANOVAs were performed with distractor type (silent, noise, semantic, and unrelated), response type (old and new), and set type ( 1 and 2 ) as the main factors.

The only effects of note concerned the main effect of response type (see Figure 3). RTs were faster on old items $(677 \mathrm{msec})$, than on new ones $\left[738 \mathrm{msec} ; F_{1}(1,18)=\right.$ $\left.15.40, M S_{\mathrm{e}}=9,671 ; F_{2}(1,19)=15.02, M S_{\mathrm{e}}=10,749\right]$. There were also more errors on old items $(8 \%)$ than on 


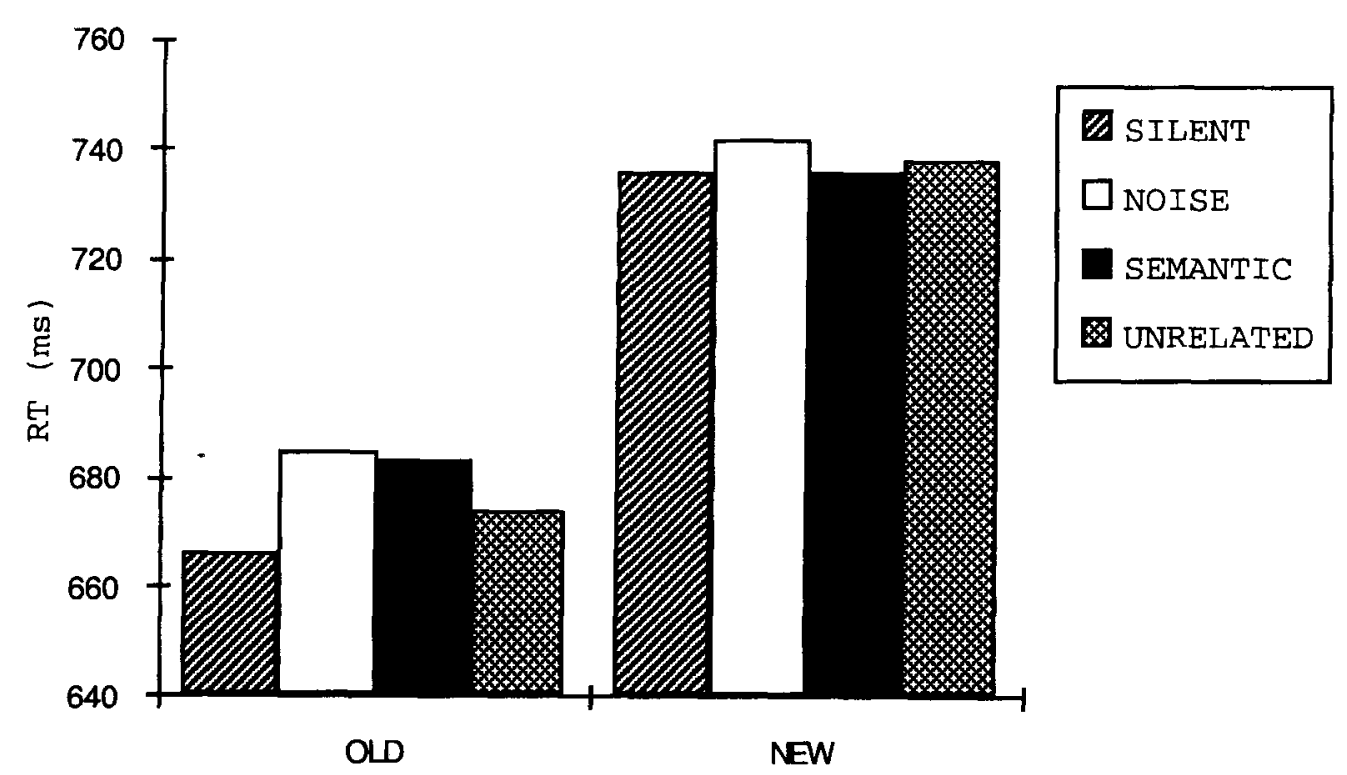

Figure 3. Mean response times (RTs, in milliseconds) as a function of distractor type and response type in Experiment 2.

new ones $\left[4 \% ; F_{1}(1,18)=8.04, M S_{\mathrm{e}}=0.009 ; F_{2}(1,19)=\right.$ $\left.12.43, M S_{\mathrm{e}}=0.006\right]$.

\section{Discussion}

Experiment 2 was designed to determine whether the semantic interference effect obtained in a written picturenaming task with an SOA value of -150 msec could be ascribed to a conceptual-processing level. Thus in Experiment 2 , a task requiring perceptual encoding and conceptual activation but no overt language production was chosen. Since no semantic interference effect was observed in the task, the results showed that the semantic interference effect is not located at a conceptual level. A further argument in support of this conclusion is that if the semantic interference effect were located at the conceptual level, it would not be affected by factors that are assumed to be located at the lexeme level, such as phonological relatedness (to anticipate the results, it is; see Experiment 3).

To summarize, the findings of Experiments 1 and 2 show that the semantic interference effect is rooted in a lexical level and, more specifically, that if the logic of Schriefers et al. (1990) is followed, it can be attributed to the lemma level. Because the flow of activation from the lemma level to the lexeme level is discrete and strictly serial, the semantic interference effect cannot be affected by factors that are assumed to act at the lexeme level, such as phonological relatedness. However, this aspect is a subject of intense debate in the literature and has strong implications for the strict discrete-serial view of language production. The next experiment addressed this issue.

\section{EXPERIMENT 3}

So far, we have addressed the time course of activation of semantic representations in spoken and written picture naming, and the findings are clear-cut. Experiment 1 showed that the semantic interference effect was reliably observed in written picture naming at the same SOA value as that for spoken picture naming and, given that this effect was not obtained in a task that required picture recognition (Experiment 2), accounts of Stroop-like interference that localize the semantic interference effect at the conceptual level can be discarded (e.g., Seymour, 1977). The similarity of these findings for spoken and written picture naming strongly suggests that the processes involved are similar for both word production systems. However, the time course of phonological representations (i.e., lexemes) has not yet been investigated. In Experiment 3, the time course of the activation of lexeme representations was addressed together with that of semantic representations. In line with the discrete-serial view as proposed by Schriefers et al. (1990), lexeme retrieval strictly follows semantic activation and selection. As has already been explained, the evidence favoring such a view is that, in Schriefers et al.'s experiments, no SOA was found at which both semantic interference and phonological facilitation were observed. According to these authors, the semantic interference effect acts at the lemma level, and the phonological facilitation is located at the lexeme level. Since these processing levels are connected in a strict serial manner, the semantic interference effect located at the lemma level cannot be affected by a factor that is assumed to take place at the lexeme level, such as phonological relatedness. However, as we will indicate below, certain findings have shown that semantic interference is modified by phonological relatedness (Starreveld \& La Heij, 1995, 1996).

Considerable controversy thus surrounds the interpretation of the semantic interference effect in conceptually driven production tasks. According to Schriefers et al.'s 
(1990) view, the semantic interference is thought to arise as follows. The unrelated word activates its lemma node, but not the picture lemma node, whereas the semantically related word activates both its lemma node and (via connections at the conceptual level) the target lemma node. The picture activates the target lemma node and the semantically related lemma node, but not the unrelated lemma node. The interference is thought to be the result of a tradeoff between the priming of the distractor lemma node by the picture and the priming of the picture lemma node by the distractor word. In addition, these authors assume that the stages of lemma selection and lexeme retrieval are discrete, which implies that the semantic interference effect cannot be modified by factors that affect the lexeme level.

A different explanation of the semantic interference effect was put forward by La Heij (1988), Glaser and Glaser (1989), and, more recently, Starreveld and La Heij (1995). According to this explanation, which could be referred to as the lexeme account of semantic interference, the semantic interference effect occurs at the lexeme level: The semantically related distractor receives extra activation from the processing of the target picture, as compared with the unrelated distractor. In this case, the semantic interference effect is thought to be due to the extra time needed to resolve the competition between the relevant lexeme corresponding to the picture and the semantically related lexeme activated by the visual (or auditory) processing of the word. According to Starreveld and La Heij (1995), if the semantic effect is located at a different level from the phonological effect and if the two stages of lemma and lexeme retrieval are strictly serial, the effects of factors affecting the semantic level (lemmas) and those of factors affecting the lexeme level should be additive. However, if these contextual factors interact, this is evidence that the phonological facilitation effect and the semantic interference effect occur at the same processing level - the lexeme level. Using a picture- and a definitionnaming task, Starreveld and La Heij $(1995,1996)$ showed that the semantic interference effect was greatly reduced when the distractor words were orthographically/phonologically related to the target names. Hence, their results supported the lexeme view of the semantic interference effect.

The critical aspect tested in Experiment 3 was to determine what would happen to the semantic interference effect when phonologically related distractors were used. This aspect is directly relevant to our general intention of determining whether spoken and written picture naming involve similar processes. Given that the discrete-serial view has been proposed for written picture naming (Ellis, $1982,1984,1988$ ) and strongly argued for by Schriefers et al. (1990) in the case of spoken picture naming, and given equally that this latter claim has been challenged by the finding of an interaction between semantic and phonological factors, the finding of an interaction between phonological and semantic factors in Experiment 3 would have strong implications for a strict discrete-serial view of written picture naming. In Experiment 3, the same design as that in Experiment 1 was used. The distractors that accompanied the pictures were created by the factorial combination of semantic and phonological relatedness. Since we were focusing on written picture naming, only a written picture-naming task was used. It is worth noting that the distractors used for Experiment 3 were presented auditorily, as in Experiments 1 and 2. This point is important, since Starreveld and La Heij $(1995,1996)$ used visually presented distractors, whereas Schriefers et al. used auditorily presented distractors. The difference between these studies in the observed time course of phonological facilitation might have been due to the use of different distractor modalities. We shall return to this point in the discussion of Experiment 3.

The critical predictions tested in Experiment 3 were as follows. According to the strict discrete-serial view, as proposed by Schriefers et al. (1990), the semantic interference effect, localized at the lemma level, should not be affected by an additional phonological relation between the distractors and the names of the picture. Therefore, on the basis of the results from Experiment 1, it was predicted that, with an SOA of $-150 \mathrm{msec}$, a semantic interference effect would be observed with both phonologically related distractors and phonologically unrelated distractors but that there would be no phonological facilitatory effect. With an SOA of $0 \mathrm{msec}$, a facilitatory effect of phonologically related distractors was predicted, but no semantic interference effect. According to the lexeme account of the semantic interference effect, since both semantic and phonological relatedness affect the lexeme level, these two factors should interact. Thus, a reduction of the semantic interference effect was predicted with phonologically related distractors, but not with phonologically unrelated distractors.

\section{Method}

Participants. Twenty-six students from Bourgogne University and from Blaise Pascal University (Clermont-Ferrand II) took part in the experiment and were given course credits. All had normal or corrected-to-normal vision and no known hearing deficits, and none had participated in any of the previous experiments.

Materials. Twenty-two line drawings of common objects served as the experimental pictures, and six additional pictures were used as warm-ups. The drawings were selected from the same corpus as that in Experiment 1 . The average frequency of the picture names was 3,846 , and the mean number of letters and syllables was six and two, respectively. The auditory distractors were created by the factorial combination of semantic and phonological relatedness. Four categories of distractors were created: semantically and phonologically related, semantically related but phonologically unrelated, semantically unrelated but phonologically related, and semantically and phonologically unrelated.

To ensure that the semantically and phonologically related distractors were not more associatively related to the picture names than were the semantically related and phonologically unrelated distractors, we asked 28 participants (not involved in Experiment 3 ) to quickly write down the first five words that came to their minds when hearing a given word. The words presented were the selected 


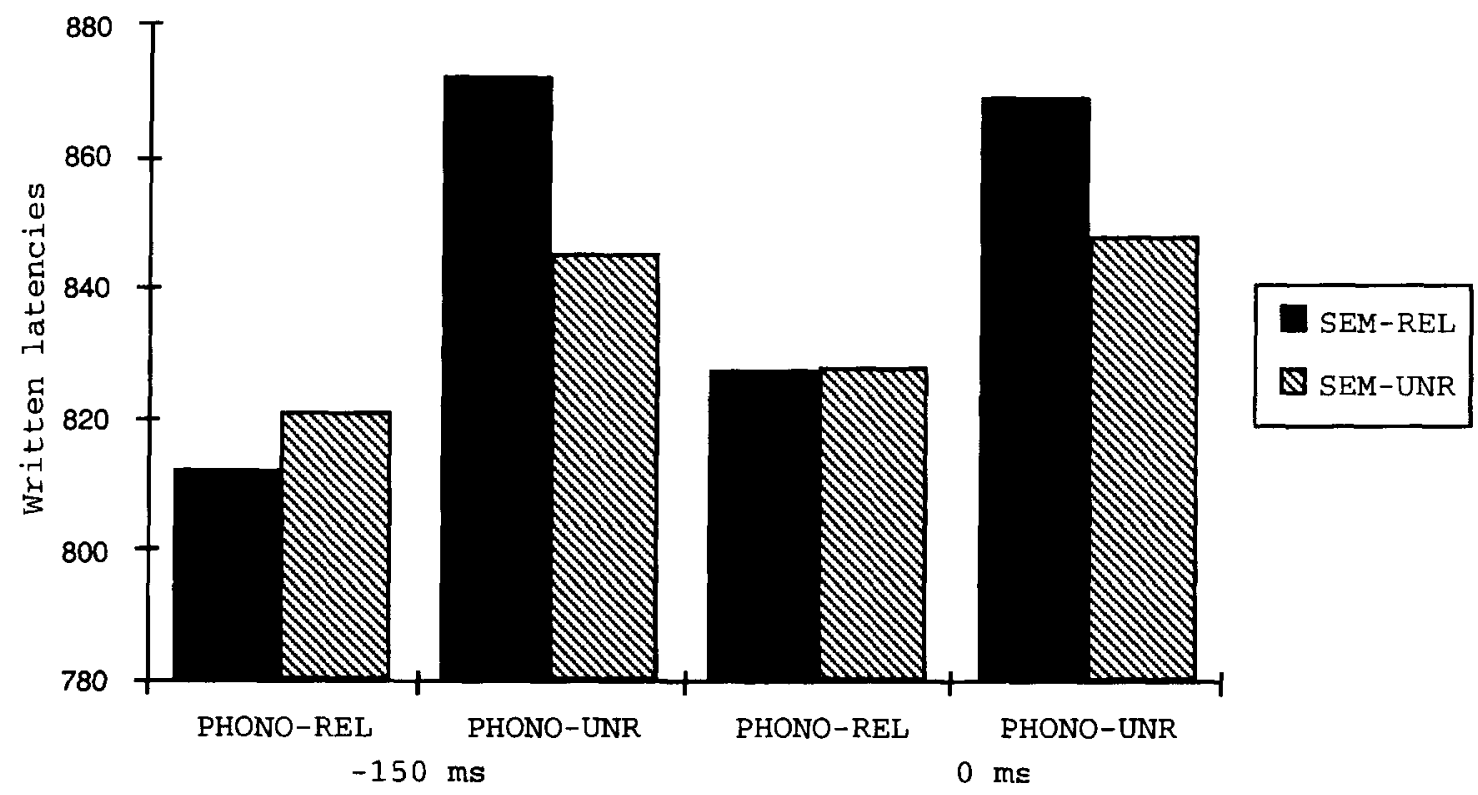

Figure 4. Mean latencies for written responses (in milliseconds) as a function of stimulus onset asynchrony, semantic relatedness (related, SEM-REL; unrelated, SEM-UNR), and phonological relatedness (related, PHONO-REL; unrelated, PHONO-UNR) in Experiment 3.

picture names. The analyses revealed that the probability of participants producing a selected distractor word was low and did not differ significantly between the semantically and phonologically related condition and the semantically related and phonologically unrelated condition (.10 and .07 , respectively).

The percentage of phonological overlap and orthographic overlap with the picture names, defined as the number of phonemes and graphemes of a given distractor with the same position as that in a given target picture name, was $39 \%$ and $34 \%$ for the semantically and phonologically related condition, $34 \%$ and $31 \%$ for the semantically unrelated and phonologically related condition, $2 \%$ and $2 \%$ for the semantically related and phonologically unrelated condition, and $1 \%$ and $2 \%$ for the semantically and phonologically unrelated condition. Since the sets of distractors differed across experimental conditions (see Appendix B), we were careful to avoid allowing any possible difference between them to contribute to RT differences between experimental conditions. Thus, the mean frequency was 2,916 for the semantically and phonologically related condition, 3,839 for the semantically related and phonologically unrelated condition, 3,631 for the semantically unrelated and phonologically related condition, and 3,051 for the semantically and phonologically unrelated condition. The number of letters was 6.45 , $6.45,6.41$, and 6.18 , respectively. The mean number of syllables was two in all the distractor conditions. Finally, the acoustic duration of the distractors (in milliseconds), was the same across conditions: on average, $851,851,853$, and 850 , respectively.

Design. There were three crossed within-subjects factorsnamely, SOA, with two levels ( -150 and $0 \mathrm{msec}$ ), semantic relatedness, with two levels (related and unrelated), and phonological relatedness, with two levels (related and unrelated). We used the same criteria as those in Experiment 1 to create four groups of 22 picture-distractor pairs. Different random orders for each of these subgroups of items were created while applying the same criteria as those described in Experiment 1.
Apparatus. The apparatus was the same as that in Experiment 1. Procedure. The procedure was the same as that used in Experiment 1 .

\section{Results}

The same exclusion criteria as those in Experiment 1 were applied to the trials. Overall, $4.11 \%$ of the data was discarded. The procedures for analyzing the data were analogous to those described for Experiment 1.

Phonologically related distractors were found to facilitate latencies for written responses, as compared with phonologically unrelated distractors $\left[F_{1}(1,25)=24.75\right.$, $\left.M S_{\mathrm{e}}=2,789.77 ; F_{2}(1,21)=24.30, M S_{\mathrm{e}}=2,598.35\right]$. As can be seen in Figure 4, the magnitude of the facilitatory effect from phonological relatedness did not vary significantly across SOAs $\left(F_{1}<1 ; F_{2}=1.32\right)$. Latencies for written responses were slowed down by a semantic relation, but this effect was significant for participants only $\left[F_{1}(1,25)=7.28, M S_{\mathrm{e}}=626.50 ; F_{2}=1.71\right]$ and was not significantly modulated by SOA $\left(F_{1}<1 ; F_{2}<1\right)$.

The most important finding in this experiment was that the effect of semantic relatedness varied across the levels of phonological relatedness (see Figure 4). This interaction effect was significant for participants $\left[F_{1}(1,25)=\right.$ $\left.11.72, M S_{\mathrm{c}}=925.78\right]$ and just failed to reach significance for items $\left[F_{2}(1,21)=3.98, M S_{\mathrm{e}}=2,557.97, p=.059\right]$. Planned comparisons indicated that a semantic interference effect was reliably observed for both participants and items with phonologically unrelated words $(+24 \mathrm{msec})$, and that it was eliminated with phonologically related 
words $(-5 \mathrm{msec})$. The triple interaction between phonological relatedness, semantic relatedness, and SOA was not significant $\left(F_{1}\right.$ and $\left.F_{2}<1\right)$, which shows that the interaction between semantic relatedness and phonological relatedness did not differ statistically across the two SOA values (see Figure 4). In the error analyses, no main effects or interactions were significant.

\section{Discussion}

Experiment 3 clearly showed that semantic and phonological relatedness interacted in such a way that the semantic interference effect was observed with phonologically unrelated distractors and was eliminated with phonologically related distractors. A phonological facilitation effect was observed at both SOA values. This finding clearly established that the observation of no early phonological effect in Schriefers et al. (1990) and of an early effect in Starreveld and La Heij (1996) is not due to a difference in distractor modality. This pattern of results strongly suggests that the strict seriality assumption strongly claimed for spoken picture naming by Schriefers et al. does not hold true for written picture naming. Remember that in Experiment 1, semantic interference in written picture naming was only observed with the use of an SOA of $-150 \mathrm{msec}$. The finding from Experiment 3, that the magnitude of the semantic interference effect with phonologically unrelated distractors did not vary significantly across SOAs, indicates that the semantic interference effect cannot be confined to the use of an SOA of $-150 \mathrm{msec}$ with auditorily presented distractors. Because the picture names and the distractors were different between these two experiments, we can only speculate that this discrepancy can be attributable to these differences in the materials.

A very important consideration is the fact that the interaction of semantic relatedness and phonological relatedness was obtained with auditorily presented distractors. To date, such an interaction had only been reported with visually presented distractors (Starreveld \& La Heij, 1995 , 1996). This result is important, since it has been argued that the difference between input presentation modes might underlie the different time courses of orthographic and phonological facilitation. Specifically, the difference in the time courses of activation of orthographic and phonological distractors has been put forward to explain why Starreveld and La Heij (1995, 1996) found an interaction between semantic and orthographic/phonological factors and Schriefers et al. (1990) found no facilitatory effect of phonological distractors at an early SOA (i.e., $-150 \mathrm{msec}$ ). Our findings clearly showed that semantic and phonological relatedness also interacted when the distractors were presented auditorily. Therefore, one of the main contributions of Experiment 3 lies in the fact that it showed that the distractor input modality is not crucial.

\section{GENERAL DISCUSSION}

Substantial research has been devoted to lexical access in conceptually driven spoken naming tasks, but this has not been the case for writing. It has often been claimed that writing is entirely dependent on spoken language representations and processes (Aitchinson \& Todd, 1982; Frith, 1979; Geschwind, 1969; Hotopf, 1980; Luria, 1970). However, such a claim has not yet received clear empirical support and is essentially based on intuitive arguments. Thus, the experimental study of lexical access in writing should address this point. The present study was designed as an attempt to determine what representations are indeed activated during the time course of lexical access in written picture naming and focused specifically on semantic and lexeme representations.

What, then, can be learned from our experiments? Experiment 1 , in which the participants had to either write down or say aloud the names of pictures while hearing distractors, showed a clear interference effect from distractors semantically related to the picture names. This effect was observed only at an early point in lexical access (with an SOA of $-150 \mathrm{msec}$ ). Experiment 2 showed that the semantic interference effect is not located at a conceptual level. At an empirical level, the findings of Experiments 1 and 2 extend to the written production of picture names a number of findings reported in spoken picture-naming studies, showing that written picture naming is very similar to spoken picture naming with respect to the time course of the semantic interference. Experiment 3 was designed to test whether the semantic interference effect obtained in Experiment 1 would be affected by a factor, phonological relatedness, that is assumed to take place at a level different from that of the semantic interference effect (the lexeme level), since such a finding would shed light on the relative time course of activation of lexeme and semantic representations. Experiment 3 clearly established that the semantic interference effect was eliminated when semantically and phonologically related distractors were used. The results of Experiment 3 are of special importance because the early phonological facilitation effect and the interaction between semantic and orthographic/phonological relatedness reported by Starreveld and La Heij $(1995,1996)$ are replicated with the French language, a different task (writing instead of naming), a very small word-form overlap between distractors and targets, and auditorily presented distractors (instead of the visually presented distractors used by Starreveld and La Heij). This last point must be emphasized because, as was already mentioned in the Discussion section of Experiment 3, it has been suggested that the difference in the mode of distractor presentation may account for discrepancies in the literature regarding the time course of phonological/ orthographic context effects.

As regards the interaction between the semantic and the phonological contexts found in Experiment 3, Roelofs et al. (1996) claimed that this interaction can be accounted for by serial stage models by assuming that there is a phonological effect at the lemma level. However, the phonological facilitation effect was $-24 \mathrm{msec}$ (phonological-unrelated). According to Roelofs et al. (1996), this is due to facilitation at the lemma level and fa- 
cilitation at the lexeme level. In Experiment 3, a $+27 \mathrm{msec}$ semantic interference effect was reduced to $-9 \mathrm{msec}$ owing to phonological similarity. It seems reasonable to assume that this huge reduction can only occur when the phonological effect at the lemma level is substantial (in Figure 3 of Roelofs et al., 1996, a 100\% reduction was only obtained with $100 \%$ orthographic similarity). There are two problems with this account: (1) The degree of phonological similarity in Experiment 3 was small, and (2) if the phonological facilitation effect at the lemma level is very large, the implication is that orthographic/ phonological similarity hardly affects lexeme retrieval. This seems rather odd, given the fact that this level is always assumed to be the genuine locus of phonological facilitation.

One aspect that deserves a brief comment concerns the lemma level as the locus of the semantic interference effect and, more generally, the existence of an obligatory lemma level between concepts and lexemes. It is clear that our data do not provide any evidence against a lemma level. However, the interaction between semantic and phonological factors found in Experiment 3 challenges the lemma level as the locus of the semantic interference effect in the strict seriality assumption. Our data can be explained by the lexeme account of the semantic interference effect (Starreveld \& La Heij, 1995). However, this critical interaction can also be explained by interactive models that do assume a lemma level (Dell, 1986, 1988, 1990; Dell \& O'Seaghdha, 1992). It is clear that future research will have to investigate the issue of whether an amodal lexical level of representations (i.e., the lemma level) is really needed to mediate between concepts and lexemes in conceptually driven naming tasks (for arguments against an obligatory lemma level, see Caramazza, 1997; Caramazza \& Miozzo, 1998).

The main findings of our study can be easily summarized: (1) Semantic similarity and phonological similarity have similar effects in spoken and written picture naming, a fact that strongly suggests that similar processes underlie these two forms of language production; (2) phonological similarity has an effect at an early SOA, a finding that indicates that the discrepancy in the literature (no early phonological effect in Schriefers et al., 1990, vs. the presence of an early effect in Starreveld \& La Heij, 1996) is not due to a difference in distractor modality and that when the rationale behind Schriefers et al.'s study is followed, an early phonological effect is not in accordance with strictly serial models of language production; and last but not least, (3) semantic similarity and phonological similarity interact, a finding that is difficult to explain by strict discrete-serial models.

To conclude, the strength of this study lies in the fact that it generalizes the findings obtained in research on spoken picture naming to the realm of written picture naming. Likewise, our findings highlight constraints that will have to be taken into account when proposing models of lexical access in written picture naming. Although the data do not allow us to propose a fully developed view of lexical access in written picture naming, they are use- ful in outlining a view that can be used as "a target to shoot at." However, what is clear from the present study is that the findings do not fit with a view of lexical access in written picture naming that assumes that activation from semantics is discretely and serially transmitted to lexemes. Further work clearly is needed to determine whether semantic activation is transmitted to lexemes in a cascaded or an interactive manner (this aspect is currently discussed in the spoken word production literature; Jescheniak \& Schriefers, 1997, 1998; Peterson \& Savoy, 1998). From a methodological point of view, the picture-word interference paradigm also appears to be a useful tool for the investigation of lexical access in written picture naming.

\section{REFERENCES}

Aitchinson, J., \& TODD, P. (1982). Slips of the mind and slips of the pen. In B. N. Chir \& W. von Raffler-Engel (Eds.), Language and cognitive styles: Patterns of neurolinguistic and psycholinguistic development (pp. 180-194). Lise: Swets \& Zeitlinger.

Bock, J. K., \& LEVELT, W. J. M. (1994). Language production: Grammatical encoding. In M. A. Gernsbacher (Ed.), Handbook of psycholinguistics (pp. 945-984). New York: Academic Press.

Bonin, P. (1995). Accès lexical en production verbale: Essai de mise en évidence d'une spécificité de l'écrit [Lexical access in language production: Toward a specialty of writing]. Unpublished doctoral dissertation. Université de Bourgogne.

Bonin, P. (1997). Produire des mots oralement et par écrit [Producing words in writing and in speaking]. Revue de Neuropsychologie, 7, 29-70.

Bonin, P., \& FAyOL, M. (1996a). L'étude en temps réel de la production du langage écrit: Pourquoi et comment [On-line study of written production; Why and how]. Etudes de Linguistique Appliquée, 101, 8-20.

Bonin, P., \& FAYOL, M. (1996b). Producing isolated words from pictures, from orally and visually presented words: An on-line study of naming and writing. In G. Rijlaarsdam, H. van den Bergh, \& M. Couzjin (Eds.), Theories, models and methodology in writing research (pp. 145-158). Amsterdam: Amsterdam University Press.

Bonin, P., FAyol, M., \& Gombert, J. E. (1997). Role of phonological and orthographic codes in picture naming and writing: An interference paradigm study. Current Psychology of Cognition, 16, 299-320.

Bonin, P., FAyol, M., \& Gombert, J. E. (1998). An experimental study of lexical access in the writing and naming of isolated words. International Journal of Psychology, 33, 269-286.

Bonin, P., Fayol, M., \& Peereman, R. (1998). Masked form priming in writing words from pictures: Evidence for direct retrieval of orthographic codes. Acta Psychologica, 99, 311-328.

Bub, D., Black, S., Hampson, E., \& Kertesz, A. (1988). Semantic encoding of pictures and words: Some neuropsychological observations. Cognitive Neuropsychology, 5, 27-66.

BUTTERWORTH, B. L. (1989). Lexical access in speech production. In W. Marslen-Wilson (Ed.), Lexical representation and process (pp. 108135). Cambridge, MA: MIT Press.

CARAmazzA, A. (1997). How many levels of processing are there in lexical access? Cognitive Neuropsychology, 14, 177-208.

Caramazza, A., \& Hillis, A. E. (1990). Where do semantic errors come from? Cortex, 26, 95-122.

Caramazza, A., \& Miozzo, M. (1998) More is not always better: A response to Roelofs, Meyer, and Levelt. Cognition, 69, 231-241.

Clark, H. H. (1973). The language-as-fixed-effect fallacy: A critique of language statistics in psychological research. Journal of Verbal Learning \& Verbal Behavior, 12, 335-359.

Cohen, J., MacWhinney, B., Flatt, M., \& Provost, J. (1993). PsyScope: An interactive graphic system for designing and controlling experiments in the psychology laboratory using Macintosh computers. Behavior Research Methods, Instruments, \& Computers, 25, 257-271.

Content, A., Mousty, P., \& Radeau, M. (1990). Brulex: Une base de données informatisée pour le français écrit et parlé [Brulex: A computerized database for written and spoken French]. L'Année Psychologique, 90, 551-566. 
DELL, G. S. (1986). A spreading-activation theory of retrieval in sentence production. Psychological Review, 93, 283-321.

DELL, G. S. (1988). The retrieval of phonological forms in production Tests of prediction from a connectionist model. Journal of Memory \& Language, 27, 124-142.

DELL, G. S. (1990). Effects of frequency and vocabulary type on phonological speech errors. Language \& Cognitive Processes, 5, 313-349.

DelL, G. S., \& O'Seaghdha, P. G. (1992). Stages of lexical access in language production. Cognition, 42, 287-314

ELLIS, A. W. (1982). Spelling and writing (and reading and speaking). In A. W. Ellis (Ed.), Normality and pathology in cognitive functions (pp. 113-146). London: Academic Press.

ElLIs, A. W. (1984). Spelling and writing. In A. W. Ellis (Ed.), Reading, writing and dyslexia: A cognitive analysis (pp. 60-85). Hillsdale, NJ: Erlbaum.

ELLIS, A. W. (1988). Spelling and writing. In A. W. Ellis \& A. W. Young (Eds.), Human cognitive neuropsychology (pp. 163-190). Hillsdale, NJ: Erlbaum.

FrITH, U. (1979). Reading by eye and writing by ear. In P. A. Kolers, M. Wrolstad, \& H. Bouma (Eds.), Processing of visible language: $I$. New York: Plenum.

GESCHWIND, N. (1969). Problems in the anatomical understanding of aphasia. In A. L. Benton (Ed.), Contributions of clinical neuropsychology. Chicago: University of Chicago Press.

Glaser, W. R., \& GLASER, M. O. (1989). Context effects in Stroop-like word and picture processing. Journal of Experimental Psychology: General, 118, 13-42.

HarLeY, T. A. (1984). A critique of top-down independent levels of speech production: Evidence from non-plan-internal speech errors. Cognitive Science, 8, 191-219.

НотоPF, N. (1980). Slips of the pen. In U. Frith (Ed.), Cognitive processing in spelling (pp. 287-307). London: Academic Press.

HumpHrEYs, G. W., RidDOCH, M. J., \& QuinlaN, P. T. (1988). Cascade processes in picture identification. Cognitive Neuropsychology, 5 , 67-103.

Jescheniak, J. D., \& Schriefers, H. (1997). Lexical access in speech production: Serial or cascaded processing? Language \& Cognitive Processes, 12, 847-852.

Jescheniak, J. D., \& Schriefers, H. (1998). Discrete serial versus cascaded processing in lexical access in speech production: Further evidence from the coactivation of near-synonyms. Journal of Experimental Psychology: Learning, Memory, \& Cognition, 24, 1256-1274.

KinSBouRne, M., \& WARRINGTON, E. K. (1964). Observations on color agnosia. Journal of Neurology, Neurosurgery, \& Psychiatry, 27, 296299.

LA HEIJ, W. (1988). Components of Stroop-like interference in picture naming. Memory \& Cognition, 16, 400-410.

la Hej, W, de Bruyn, E., Elens, E., Hartsuiker, R., Helaha, D., \& VAN SCHELVEN, L. (1990). Orthographic facilitation and categorical interference in a word-translation variant of the Stroop task. Canadian Journal of Psychology, 44, 76-83.

La Heis, W., Dirkx, J., \& Kramer, P. (1990). Categorical interference and associative priming in picture naming. British Journal of Psychology, 81, 511-525.

La HeiJ, W., Starreveld, P. A., \& Steehouwer, L. C. (1993). Semantic interference and orthographic facilitation in definition naming. Journal of Experimental Psychology: Learning, Memory. \& Cognition, 19, 352-368.

LA HEIJ, W., \& VAN DEN HoF, E. (1995). Picture-word interference increases with target-set size. Psychological Research, 58, 119-133.

LEVELT, W. J. M. (1989). Speaking: From intention to articulation. Cambridge, MA: MIT Press.

LEVELT, W. J. M. (1991). Lexical access in speech production: Stages vs. cascading. In H. F. M. Peters, W. Hulstijn, \& C. W. Startweather (Eds.), Speech motor control and stuttering (pp. 3-10). New York: Elsevier.

LEVELT, W. J. M. (1992). Accessing words in speech production: Stages, processes and representations. Cognition, 42, 1-22.

Levelt, W. J. M., Schriefers, H., Vorberg, D., Meyer, A. S., Pech-
ManN, T., \& Havinga, J. (1991a). Normal and deviant lexical processing: Reply to Dell and O'Seaghdha (1991). Psychological Review, 98, 615-618.

Levelt, W. J. M., Schriefers, H., Vorberg, D., Meyer, A. S., PechManN, T., \& Havinga, J. (199lb). The time course of lexical access in speech production: A study of picture naming. Psychological Review, 98, 122-142.

LURIA, A. R. (1970). Traumatic aphasia. The Hague: Mouton.

MARGOLIN, D. I. (1984). The neuropsychology of writing and spelling: Semantic, phonological, motor, and perceptual processes. Quarterly Journal of Experimental Psychology, 36A, 459-489.

Meyer, A. S., \& Schriefers, H. (1991). Phonological facilitation in picture-word interference experiments: Effect of stimulus onset asynchrony and types of interfering stimuli. Journal of Experimental Psychology: Learning, Memory, \& Cognition, 17, 1146-1160.

Peterson, R. R., \& Savoy, P. (1998). Lexical selection and phonological encoding during language production: Evidence for cascaded processing. Journal of Experimental Psychology: Learning, Memory, \& Cognition, 24, 539-557.

Rapp, B., Benzing, L., \& Caramazza, A. (1997). The autonomy of lexical orthography. Cognitive Neuropsychology, 14, 71-104.

RaYNer, K., \& SPRINGer, C. (1986). Graphemic and semantic similarity effects in the picture-word interference task. British Journal of Psychology, 77, 207-222.

RoELOFS, A. (1992). A spreading-activation theory of lemma retrieval in speaking. Cognition, 42, 107-142.

Roelofs, A., MEYer, A. S., \& Levelt, W. J. M. (1996). Interaction between semantic and orthographic factors in conceptually driven naming: Comment on Starreveld and La Heij (1995). Journal of Experimental Psychology: Learning, Memory, \& Cognition, 22, 246-251.

Roelofs, A., Meyer, A. S., \& Levelt, W. J. M. (1998). A case for the lemma/lexeme distinction in models of speaking: Comment on Caramazza and Miozzo (1997). Cognition, 69, 219-230.

SCHRIEFERS, H. (1990). Lexical and conceptual factors in the naming of relations. Cognitive Psychology, 22, $111-142$.

Schriefers, H. (1992). Lexical access in the production of noun phrases. Cognition, 45, 33-54.

Schriefers, H., Meyer, A. S., \& Levelt, W. J. M. (1990). Exploring the time course of lexical access in langage production: Picture-word interference studies. Journal of Memory \& Language, 29, 86-102.

SEYmour, P. H. K. (1977). Conceptual encoding and the locus of the Stroop-effect. Quarterly Journal of Experimental Psychology, 29, 245265.

Snodgrass, J. C., \& Vanderwart, M. (1980). A standardized set of 260 pictures: Norms for names agreement, image agreement, familiarity, and visual complexity. Journal of Experimental Psychology: Human Learning \& Memory, 6, 174-215.

Starreveld, P. A., \& La Heis, W. (1995). Semantic interference, orthographic facilitation and their interaction in naming tasks. Journal of Experimental Psychology: Learning, Memory, \& Cognition, 21, 686-698.

Starreveld, P. A., \& LA HeiJ, W. (1996). The locus of orthographicphonological facilitation: Reply to Roelofs, Meyer, and Levelt (1996). Journal of Experimental Psychology: Learning, Memory, \& Cognition, 22, 1-4.

Vaughan, J., \& Yee, P. L. (1994). Using PsyScope for demonstrations and student-designed experiments in cognitive psychology courses. Behavior Research Methods, Instruments, \& Computers, 26, 142-147.

\section{NOTES}

1. In the following experiments, no attempt was made to disentangle phonological effects from orthographic effects in written picture naming (on this issue, see Bonin et al., 1997; Bonin, Fayol, \& Peereman, 1998; for a review, see Bonin, 1997). For the sake of simplicity, we shall simply speak of phonological effects and phonological relatedness.

2. Moreover, La Heij and Van den Hof (1995) demonstrated that the semantic interference effect increases with target-set size (i.e., the number of target pictures used in an experiment). 
APPENDIX A

Materials From Experiments 1 and 2

\begin{tabular}{|c|c|c|}
\hline \multirow[b]{2}{*}{ Picture Name } & \multicolumn{2}{|c|}{ Distractor Type } \\
\hline & Semantic & Unrelated \\
\hline gant & robe & barque \\
\hline (glove) & (dress) & (barge) \\
\hline étoile & terre & casque \\
\hline (star) & (earth) & (helm) \\
\hline poisson & crevette & drapeau \\
\hline (fish) & (shrimp) & (flag) \\
\hline marteau & écrou & livre \\
\hline (hammer) & (screw) & (book) \\
\hline vélo & train & clef \\
\hline (bike) & (train) & (key) \\
\hline poire & banane & bouton \\
\hline (pear) & (banana) & (shirt button) \\
\hline cheval & cochon & verre \\
\hline (horse) & (pig) & (glass) \\
\hline botte & chaussette & montagne \\
\hline (boot) & (sock) & (mountain) \\
\hline accordéon & violon & bobine \\
\hline (accordion) & (violin) & (bobbin) \\
\hline bureau & armoire & tambour \\
\hline (desk) & (cupboard) & (drum) \\
\hline fusil & révolver & ceinture \\
\hline (steel) & (pistol) & (belt) \\
\hline râteau & arrosoir & bague \\
\hline (rake) & (watering can) & (ring) \\
\hline horloge & réveil & clou \\
\hline (clock) & (alarm clock) & (nail) \\
\hline crocodile & éléphant & échelle \\
\hline (crocodile) & (elephant) & (ladder) \\
\hline cigarette & pipe & noix \\
\hline (cigarette) & (pipe) & (nut) \\
\hline doigt & orteil & citron \\
\hline (finger) & (toe) & (lemon) \\
\hline chat & mouton & croix \\
\hline (cat) & (sheep) & (cross) \\
\hline chaise & lampe & grue \\
\hline (chair) & (lamp) & (crane) \\
\hline arbre & fleur & roue \\
\hline (tree) & (flower) & (wheel) \\
\hline tigre & ours & noeud \\
\hline (tiger) & (bear) & $(\mathrm{knot})$ \\
\hline
\end{tabular}

Note-Approximate translations of the items are given in parentheses. 
APPENDIX B

Material From Experiment 3

\begin{tabular}{|c|c|c|c|c|}
\hline \multirow[b]{2}{*}{ Picture Name } & \multicolumn{4}{|c|}{ Distractor Type } \\
\hline & $\mathrm{S}+\mathrm{P}+$ & $\mathrm{S}+\mathrm{P}-$ & $\mathrm{S}-\mathrm{P}+$ & $\mathbf{S}-\mathbf{P}-$ \\
\hline ballon & bille & raquette & banane & aigle \\
\hline (ball) & (marble) & (racket) & (banana) & (eagle) \\
\hline bonnet & béret & casquette & bonbon & fleur \\
\hline (hood) & (beret) & (cap) & (candy) & (flower) \\
\hline cahier & carnet & livre & canapé & drapeau \\
\hline (paper book) & (notebook) & (book) & (sofa) & (flag) \\
\hline camion & caravane & hélicoptère & carotte & noix \\
\hline (truck) & (caravan) & (helicopter) & (carrot) & (walnut) \\
\hline chat & chèvre & renard & champignon & roue \\
\hline (cat) & (goat) & $(f \circ x)$ & (mushroom) & (wheel) \\
\hline chaussette & chemise & veste & chenille & tétine \\
\hline (sock) & (shirt) & (jacket) & (caterpillar) & (teat) \\
\hline cheval & chien & cochon & château & bouton \\
\hline (horse) & $(\operatorname{dog})$ & (pig) & (castle) & (button) \\
\hline cigarette & cigare & pipe & ciseau & asperge \\
\hline (cigarette) & (cigar) & (pipe) & (scissors) & (asparagus) \\
\hline citron & cerise & fraise & cercle & montagne \\
\hline (lemon) & (cherry) & (strawberry) & (circle) & (mountain) \\
\hline crabe & crevette & huitre & crayon & bobine \\
\hline (crab) & (shrimp) & (oyster) & (pencil) & (bobbin) \\
\hline cuiller & couteau & fourchette & cartable & échelle \\
\hline (spoon) & (knife) & (fork) & (satchel) & (ladder) \\
\hline harpe & harmonica & guitare & hache & ceinture \\
\hline (harp) & (harmonica) & (guitar) & (axe) & (belt) \\
\hline lion & léopard & gazelle & lampe & bague \\
\hline (lion) & (leopard) & (gazelle) & (lamp) & (ring) \\
\hline narteau & massue & écrou & magnétophone & téléphone \\
\hline (hammer) & (bludgeon) & (nut) & (tape recorder) & (telephone) \\
\hline oreille & orteil & doigt & ortie & compas \\
\hline (ear) & (toe) & (finger) & (nettle) & (compass) \\
\hline poire & pomme & abricot & peigne & bougie \\
\hline (pear) & (apple) & (apricot) & (comb) & (candle) \\
\hline poireau & persil & chou & porte & grue \\
\hline (leek) & (parsley) & (cabbage) & (door) & (crane) \\
\hline table & tabouret & chaise & talon & carabine \\
\hline (table) & (stool) & (chair) & (heel) & (carbine) \\
\hline tambour & trompette & violon & toupie & croix \\
\hline (drum) & (trumpet) & (violin) & (top) & (cross) \\
\hline toit & tuile & brique & tasse & panier \\
\hline (roof) & (tile) & (brick) & (cup) & (basket) \\
\hline tracteur & train & autobus & truelle & bouteille \\
\hline (tractor) & (train) & (bus) & (trowel) & (bottle) \\
\hline vélo & voiture & avion & vase & noeud \\
\hline (bike) & (car) & (plane) & (vase) & (knot) \\
\hline
\end{tabular}

Note- $\mathrm{S}+\mathrm{P}+$, semantically and phonologically related; $\mathrm{S}+\mathrm{P}-$, semantically related and phonologically unrelated; $\mathrm{S}-\mathrm{P}+$, semantically unrelated and phonologically related; $\mathrm{S}-\mathrm{P}-$, semantically and phonologically unrelated. Approximate translations of the items are given in parentheses.

(Manuscript received July 28, 1997

revision accepted for publication April 27, 1999.) 